\title{
Corpos em Evidência: Contribuição do Mapa Corporal Narrado em Pesquisas com Populações Vulnerabilizadas*
}

\author{
Ana Luísa Coelho Moreira** (1) \& Maria Inês Gandolfo Conceição (1) \\ Universidade de Brasilia, Brasília, DF, Brasil
}

\begin{abstract}
RESUMO - O mapa corporal narrado é uma metodologia cada vez mais empregada em pesquisa. O objetivo deste estudo foi realizar uma metassíntese para sintetizar, interpretar e analisar resultados de evidências qualitativas de pesquisas sobre mapa corporal narrado com populações vulnerabilizadas e compreender que lacuna na produção de conhecimento o seu uso visa a suprir. As bases de dados/bibliotecas foram Web of Science, Proquest, BVS, Scopus, Ebsco, SciELO e PubMed, resultando em 4.050 registros. Após a aplicação dos critérios de inclusão/exclusão, foram recuperados oito artigos. A síntese das evidências qualitativas foi organizada em três categorias de análise: (1) inovação criativa; (2) potencial terapêutico; (3) metodologia emancipatória. Conclui-se que a ferramenta alinha-se com o paradigma emancipatório e crítico e dialoga com a psicologia clínica e comunitária.
\end{abstract}

PALAVRAS-CHAVE: mapa corporal, pesquisa qualitativa, prática clínica baseada em evidência, populações vulneráveis

\section{Bodies in Evidence: Contribution of Body-map Storytelling in Research with Vulnerable Populations}

\begin{abstract}
The body-map storytelling is a methodology increasingly used in research. The objective was to carry out a meta-synthesis to synthesize, interpret and analyze results of qualitative evidence from research on body-map storytelling with vulnerable populations and to understand what gap is addressed in the production of knowledge with its use. The databases were Web of Science, Proquest, VHL, Scopus, Ebsco, SciELO and PubMed, resulting in 4,050 articles. After applying the inclusion/exclusion criteria, eight articles resulted. The synthesis of the qualitative evidences was organized in three categories of analysis: (1) creative innovation; (2) therapeutic potential; (3) emancipatory methodology. It is concluded that the tool is in line with the emancipatory and critical paradigm, and dialogue with clinical and community psychology.

KEYWORDS: body map, qualitative research, evidence-based practice, vulnerable population
\end{abstract}

O enfoque qualitativo em pesquisa no campo da saúde vem experimentando crescente reconhecimento e expansão, haja vista a sua capacidade de abarcar a complexidade dos fenômenos, favorecer o avanço dos conhecimentos e soluções técnicas, bem como incrementar o desenvolvimento humano nas ações em saúde (Mercado et al., 2018). Ainda que em franco crescimento, essa tradição de pesquisa encontra inúmeras barreiras - além da intransponível hegemonia da tradição positivista -, dentre as quais repontam a urgência em aprimorar a qualidade de estudos qualitativos e a necessidade de desenvolver estratégias criativas que respondam às necessidades de um público historicamente marginalizado e excluído da produção de conhecimento científico.

As pesquisas devem ser sensíveis às formas culturalmente diversas, entendendo-se o mundo em sua complexidade (Packer, 2011). Nessa esteira, estudos sobre temas sensíveis e perspectivas marginalizadas no campo da saúde demandam o desenvolvimento de metodologias que apreendam o universo de sentidos complexos, e por vezes

\footnotetext{
* Apoio: FAPDF e CNPq

** Email: analuisacm.psi@gmail.com

- Submetido: 10/10/2019; Revisado: 21/01/2020; Aceito: 20/03/2020.
} 
silenciados, conferindo importância significativa às escolhas metodológicas (Minayo, 2013).

Populações marginalizadas muitas vezes são reticentes às abordagens tradicionais de pesquisa qualitativa que valorizam exclusivamente a produção de conhecimento pelas vias racionais (tais como, entrevistas, questionários, grupos focais). As metodologias que empregam o uso das artes têm surgido como resposta a essa limitação, tendo em vista que as artes vão além das palavras, oferecendo alternativas de comunicação para transmitir a profundidade e a complexidade das experiências e emoções vividas (Baerg, 2003). Uma das novas metodologias visuais que vem sendo cada vez mais empregada, com o propósito de suprir essa lacuna na produção de conhecimento, tem sido o mapa corporal, daí a justificativa para o aprofundamento de seu estudo.

O mapa corporal é um instrumento ou método de pesquisa qualitativa que utiliza como dados as narrativas pessoais, por meio do desenho do corpo em tamanho real, usando recursos gráficos como desenhos, pinturas, colagens, fotografias, recortes de revistas, jornais e papéis (Gastaldo et al., 2012). Essa ferramenta revela-se para o campo da pesquisa qualitativa como um desafio enriquecedor, uma vez que se configura como uma metodologia visual, com potencial crítico, criativo e participativo. Os elementos que a metodologia visual do mapa corporal oferecem vão ao encontro do que pesquisa qualitativa aponta, uma vez que carregam consigo a qualidade do compromisso e da crítica como um recurso que transgride o entendimento vigente, questiona a estrutura dominante e elenca práticas que visam a "centralidade da subjetividade e da reflexividade, a interpretação, que emergem em oposição à teorização a priori dos dados, a multiplicidade de verdades, a existência de forças invisíveis como o discurso e o poder" (Eakin, 2016, p. 110).

A prática do mapa corporal difundiu-se na África do Sul, no final dos anos 1990, como recurso terapêutico para $\mathrm{o}$ atendimento de pessoas que viviam com HIV/aids. O psicólogo Jonathan Morgan, idealizador do Projeto Memory Box, em parceria com a artista Jane Solomon, desenvolveram um trabalho de arteterapia por meio de desenhos corporais e histórias de vida, com mulheres soropositivas, sobre as possibilidades de criação frente a dor e a ressignificação do luto, transformando a expectativa de morte em um novo olhar para a vida, e recontando as suas histórias através do corpo (MacGregor, 2009). Posteriormente, o mapa corporal foi adaptado e passou a ser desenvolvido no Canadá como uma metodologia de pesquisa qualitativa no campo da saúde pelas pesquisadoras brasileiras Denise Gastaldo e Lilian Magalhães. Elas desenvolveram um estudo com trabalhadores indocumentados que migraram para o país canadense e utilizaram o mapa corporal narrado como recurso visual e criativo de pesquisa, a fim de provocar uma consciência crítica acerca das experiências de vida de cada participante, uma vez que "desenhar símbolos e selecionar as imagens ajudou-os a contar uma história e, ao mesmo tempo, desafiou-os a procurar significados que representam quem eles tinham se tornado através do processo de migração." (Gastaldo et al., 2012, p. 8).

A literatura internacional sobre o uso do mapeamento corporal como método de pesquisa assenta-se nos campos das ciências sociais, saúde e educação e abarca múltiplos temas, tais como: HIV/aids (MacGregor, 2009; MacGregor \& Mills, 2011; Maina et al., 2014; Willis et al., 2018), trabalhadores indocumentados (Gastaldo et al., 2012), jovens refugiados (Davy et al., 2014), saúde sexual (Ramsuran \& Lurwengu, 2008; Senior et al., 2014), pobreza infantil (Mitchell, 2006), gravidez na adolescência (Gubrium et al., 2016), mulheres gestantes desempregadas (Ferigato et al., 2018), violência de gênero (Sweet \& Escalante, 2015), pessoas com sequelas de AVC (Gelatti \& Angeli, 2019), pessoas com múltiplas e complexas necessidades (Dew et al., 2018), pessoas com fibromialgia (Skop, 2016), público LGBT (Murasaki \& Galheigo, 2016), indígenas ou aborígenes (Lys et al., 2018; Yuen, 2016), práticas corporais (Matos et al., 2018; Tarr \& Thomas, 2011), educação e ensino (Botha, 2017; Ebersohn, 2015, Griffin, 2014).

Depreende-se, desses estudos, que não existe um método único de realização do mapa corporal, pois os estudos apresentam várias combinações e modalidades na utilização do mapa por meio do desenho do corpo em tamanho real. Outrossim, há vários modos de análise dos dados, embora não tenham sido encontrados detalhes sobre a implementação dos procedimentos de análise visual em nenhum dos trabalhos publicados (Skop, 2016). Nota-se que a maioria dos estudos trata de populações vulnerabilizadas, excluídas, estigmatizadas ou marginalizadas. Todas as pesquisas destacam o caráter criativo dessa modalidade de metodologia visual, bem como assinalam para seu caráter terapêutico.

Nos últimos cinco anos, duas revisões sistemáticas de literatura sobre mapas corporais narrados como método de pesquisa foram publicadas: (1) Jager et al. (2016) e (2) Gastaldo et al. (2018), ambas publicadas no mesmo periódico. A revisão de Jager et al. (2019) identificou 19 estudos, dos quais, seis estavam relacionados a HIV/aids e os demais envolviam uma ampla gama de temas relacionados à saúde, tais como, saúde sexual, saúde da criança, dor, trauma, luto e violência doméstica. $\mathrm{O}$ estudo concluiu que o mapa corporal permite uma reflexão mais profunda sobre o problema e elicia novas informações nos participantes. Já a revisão de Gastaldo et al. (2018) analisa 27 estudos sobre uso de mapas corporais e histórias narradas que se centram nos determinantes sociais da saúde de grupos marginalizados, e conclui que, apesar da diversidade de nomes e de estratégias de análise de dados, a metodologia revela que os participantes são considerados indivíduos reflexivos e com conhecimento para articular melhor suas complexas jornadas de vida ao desenhar seus corpos. 
Ainda que ambas as revisões de escopo explorem a utilização do mapa corporal narrado como método de pesquisa, remanescem questões sobre como os estudos respondem às lacunas referentes à produção de conhecimento, no que tange ao público estigmatizado e vulnerabilizado pelo contexto, sobretudo quanto aos aspectos da criatividade e do potencial terapêutico do método. Embora os estudos assinalem a coexistência de diferentes denominações para essa metodologia visual, nesta revisão usaremos indistintamente os termos mapeamento e mapa corporal. Assim, os estudos sobre mapa corporal narrado assinalam que o processo de elaboração sobre as próprias experiências, sentimentos, dores e memórias dá-se por intermédio da produção criativa do desenho do mapa do corpo combinada com as narrativas apresentadas pelos participantes sobre suas histórias de vida. Entretanto, algumas evidências dos estudos não foram sintetizadas e deixam lacunas: que produções de conhecimento sobre as populações vulnerabilizadas se constroem a partir do método de pesquisa do mapa corporal narrado?

A fim de refletir sobre esse hiato na produção científica, o presente estudo tem o objetivo de realizar uma metassíntese para sintetizar, interpretar e analisar resultados de evidências qualitativas de pesquisas sobre mapa corporal narrado com populações vulnerabilizadas e compreender que lacuna na produção de conhecimento o seu uso visa a suprir. Esta revisão torna-se relevante haja vista que, embora encontremos um número crescente de investigações acerca do assunto, não há estudos que apontem para a realização de uma síntese baseada em evidências qualitativas sobre a aplicação do mapa corporal em pesquisa. Espera-se que com este estudo diversas áreas do conhecimento, com destaque para a psicologia clínica, possam incorporar práticas criativas, inovadoras e que trabalhem em uma perspectiva emancipatória, considerando as experiências e culturas locais.

\section{MÉTODO}

A metassíntese qualitativa utiliza a perspectiva interpretativa por meio das evidências qualitativas agregadas, respeitando os achados nos estudos primários (Sandelowski \& Barroso, 2007). Com o advento do crescente número de investigações qualitativas, as evidências passaram a ser reconhecidas neste campo, em virtude de reunirem informações qualitativas para responder a questões complexas de forma estruturada, considerando as percepções dos envolvidos (Sousa et al., 2019). De acordo com Lockwood et al. (2017), a metassíntese cumpre etapas rigorosas para a síntese das evidências, tais como: apresentar de forma descritiva todas as etapas da revisão; realizar de forma abrangente, exaustiva e crítica a pesquisa para a extração de dados e obter transparência na síntese dos achados. A metassíntese pressupõe uma preocupação em elaborar conhecimentos, chegar a determinadas conclusões e produzir recomendações que possam auxiliar na tomada de decisões no esteio das políticas ou práticas, sobretudo no campo da saúde (Lopes \& Fracolli, 2008).

No que se refere às pesquisas sobre mapa corporal, há uma produção de evidências qualitativas que podem ser sintetizadas visando a otimizar a validade desses estudos, bem como pode capturar processos mais complexos e subjetivos inerentes à vida humana. Esse enfoque qualitativo pode contribuir significativamente para ampliar a compreensão desses processos, na medida em que utiliza dados oriundos da interação entre pesquisador e participante. Busca-se também analisar as experiências, relações sociais e compreensão de mundo por meio de falas, observações, desenhos e demais expressões dos indivíduos (Sousa et al., 2019).

Desta forma, a construção da síntese de evidências qualitativas sobre mapa corporal narrado foi organizada a partir de protocolos de revisão cuja definição das perguntas orientadoras foram definidas por meio da ferramenta mnemônica PICo (Joanna Briggs Institute for Evidence Based Practice, 2014), bastante utilizada em revisões sistemáticas de evidências qualitativas. Esse instrumento possibilitou a identificação de informações como população/ problema $(\mathrm{P})$, o fenômeno de interesse (I) e o contexto (Co) que implicaram na formulação da pergunta: A que lacunas da produção científica sobre populações vulnerabilizadas as pesquisas com mapa corporal se propõem a responder?

Destarte, a partir da pergunta, a estratégia de busca foi iniciada no primeiro semestre de 2019, após ser delineada e acordada entre as pesquisadoras (autoras do presente artigo) e o corpo assistente de bibliotecários especialistas da Universidade de Brasília. Foram realizadas buscas de artigos científicos nas bases de dados Biblioteca Virtual em Saúde (BVS), Scientific Electronic Library Online (SciELO), Web of Science, Scopus, Proquest, Ebsco e PubMed; com os seguintes descritores e operadores boleanos: "mapa corporal" OR "body map" OR "body mapping". Não foi delimitado um espaço temporal, já que o uso do mapa corporal como método de pesquisa é algo que se mostrou ser recente.

A organização de triagem, extração e registro dos dados foi realizada em duas etapas: na primeira, foi utilizado o Protocolo PRISMA (Moher et al., 2009) para sistematizar os achados, com base na pergunta orientadora, no objetivo proposto e nos critérios de inclusão/exclusão. Para especificar mais detalhadamente o universo apresentado, foi realizada uma leitura criteriosa de todos os títulos, resumos e abstracts pelas duas pesquisadoras que já desenvolvem estudos na área de mapa corporal, psicologia clínica e pesquisa qualitativa. As examinadoras analisaram, de forma 
independente, todos os trabalhos e aplicaram os critérios exigidos nos protocolos utilizados. Eventuais dúvidas ou divergência de opiniões foram solucionadas pela leitura na íntegra do artigo e tomada de decisão conjunta, mediante consenso.

Os critérios de inclusão utilizados para a seleção das produções foram: (1) artigo publicado em periódico científico; (2) texto completo disponível; (3) enquadramento de metodologia como pesquisa qualitativa ou métodos mistos; (4) idiomas em português, inglês ou espanhol; (5) conceito de mapa corporal como ferramenta ou metodologia de pesquisa qualitativa, considerando a narrativa de histórias de vida por meio de desenho do corpo inteiro, em tamanho real e com recursos artísticos como pintura, recorte de revistas e jornais, tecidos e/ou tintas.

Já os critérios de exclusão estavam relacionados a: (1) produções em duplicidade; (2) trabalhos cujos mapas corporais não foram confeccionados pelos participantes, e sim entregues prontos; (3) uso do conceito de mapa corporal divergente da delimitação da pesquisa (ex: mapa corporal como escala de identificação de dores corporais e musculares, de movimentos de performance; método orofacial, de ergonomia, de engenharia de software, de projeção audiovisual); (4) pesquisas cujo públicoalvo estudado não inclui populações vulnerabilizadas, estigmatizadas ou marginalizadas; (5) literatura cinza, livros ou capítulos; 6) estudos em que a análise da aplicação do mapa corporal não é central.

$\mathrm{Na}$ segunda etapa, as pesquisadoras organizaram uma tabela contendo as características dos estudos incluídos: autoria; ano da publicação; país; método/coleta; objetivo do estudo; características do público, local e contexto do estudo. Posteriormente, foi aplicado o protocolo Critical Appraisal Skills Programme (CASP, 2018), instrumento que visa a abordar os princípios e premissas subjacentes à pesquisa qualitativa para avaliar a qualidade dos estudos. Essa avaliação foi utilizada com o objetivo de analisar a qualidade dos artigos selecionados para a amostra final e apreciar seu rigor metodológico.

\section{RESULTADOS E DISCUSSÃO}

A busca inicial nas bases de dados com os descritores mencionados resultou em 4.050 artigos científicos assim distribuídos: BVS (269); SciELO (21); Web of Science (172); Scopus (173); Proquest (2.785); Ebsco (530) e PubMed (100). Após a aplicação dos critérios de inclusão/exclusão foram lidos na íntegra 26 publicações, das quais 18 foram elimina- das devido a: o conceito de mapa corporal ser divergente do proposto; as evidências qualitativas do mapa corporal não são exploradas; os participantes não se enquadram dentro da categoria de populações vulnerabilizadas. Dessa forma, a amostra final contou com oito artigos científicos analisados e categorizados sistematicamente (ver Figura 1).

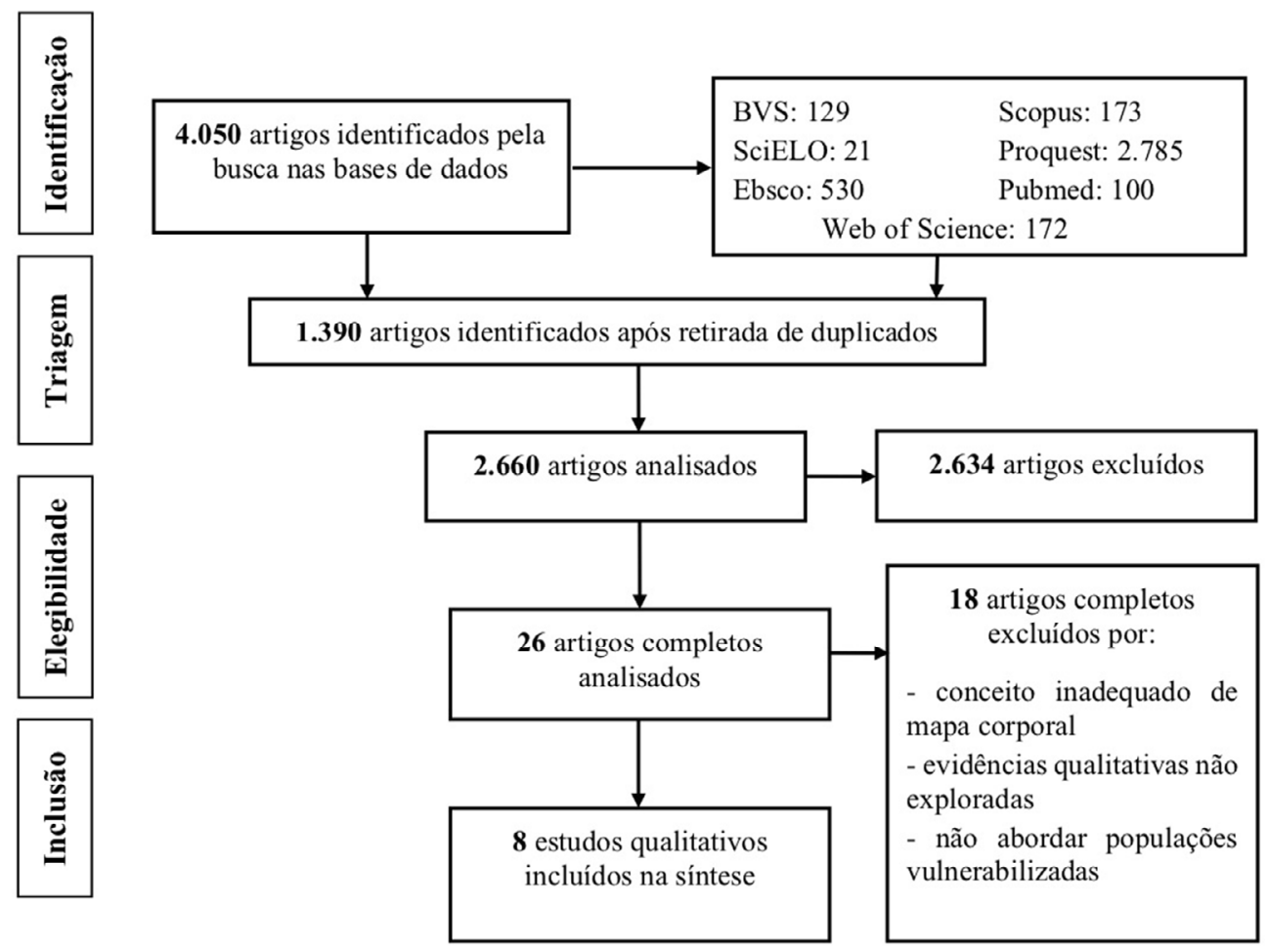

Figura 1. Diagrama do processo de seleção de artigos. Adaptado de Moher et al. (2009). 
A temática do mapa corporal como metodologia de pesquisa qualitativa é bastante recente, as publicações compreendem o período entre os anos de 2009 a 2019, com acentuada produção nos últimos cinco anos. Na amostra final, a predominância do idioma nas publicações é o inglês $(87,5 \%)$ e a maioria dos estudos foi realizada no Canadá, Brasil, Estados Unidos, Zimbábue e Austrália (ver Tabela 1). Entretanto, vale ressaltar que, dentre os achados de um modo geral, há uma presença considerável de artigos da África do Sul, uma vez que é um dos locais de origem de criação do mapa corporal. Os artigos situam-se no campo da saúde e as principais áreas de atuação das pesquisas são: Enfermagem, Terapia Ocupacional e Saúde Pública. Dentre os trabalhos descartados verificou-se que grande parte se tratava da área da medicina, com estudos de modulação de dor, ou também estudos odontológicos, ergonômicos e um residual de viés educativo com desenhos de corpos humanos para fins de ensino sobre sexualidade, uso de métodos contraceptivo e relação professor/aluno.

Observa-se que o uso do mapa corporal possui três focos principais que estão interligados: a pesquisa, a intervenção e a participação ativa. Em geral, o perfil dos participantes do mapa corporal teve predomínio de adolescentes e jovens de 15 a 29 anos, entretanto também ocorreram pesquisas em que o público foi de pessoas adultas, sobretudo quando o enfoque do estudo era sobre determinada doença crônica como AVC, fibromialgia, entre outros. Nota-se que grande parte dos grupos estudados possui um recorte de marcador social que se destaca, por exemplo, questões de renda, gênero, raça/etnia, orientação sexual, deficiência, gestação, saúde/doença, ciclos de vida, origem, migração.

No que tange aos aspectos da avaliação da qualidade, os oito artigos da amostra final foram analisados de acordo com Critical Appraisal Skills Programme (CASP, 2018), instrumento que possui 10 perguntas, tendo sido estabelecidas as seguintes pontuações: "Sim": 2 pontos, "Não sei": 1 ponto e "Não": 0 pontos. O cálculo da pontuação final correspondeu à média das avaliações realizadas pelas duas examinadoras. Foram atribuídas porcentagens a cada artigo analisado, sendo que entre 60 e $100 \%$ foram considerados como menor risco de viés metodológico e pontuações inferiores a $60 \%$ como maior risco de viés metodológico. Todas as diferenças e dúvidas entre as examinadoras foram sanadas mediante discussão, embora não tenha ocorrido nenhuma discrepância significativa na atribuição das notas.

Tabela 1

Descrição dos artigos cientificos incluidos $(N=8)$

\begin{tabular}{|c|c|c|c|c|c|}
\hline Artigo & Autor/Ano & País & Objetivo & Participante, contexto, local & Método/ coleta \\
\hline A1 & $\begin{array}{l}\text { Willis, Mavhu, } \\
\text { Wogrin, Mutsinze, } \\
\text { \& Kagee, } 2018\end{array}$ & Zimbábue & $\begin{array}{l}\text { Explorar a experiência e manifestação de } \\
\text { depressão em adolescentes que vivem com } \\
\text { HIV no Zimbábue, a fim de informar o } \\
\text { desenvolvimento da intervenção. }\end{array}$ & $\begin{array}{l}\text { Jovens HIV positivo, Centro } \\
\text { de Tratamento Zimbábue }\end{array}$ & $\begin{array}{l}\text { Entrevista e } \\
\text { mapa corporal }\end{array}$ \\
\hline A2 & Lys, 2018 & Canadá & $\begin{array}{l}\text { Avaliar a efetividade do mapeamento corporal } \\
\text { como ferramenta de intervenção e coleta de } \\
\text { dados para pesquisa em saúde mental com } \\
\text { jovens. }\end{array}$ & $\begin{array}{l}\text { Adolescentes e jovens } \\
\text { indígenas do sexo feminino, } \\
\text { comunidade localizada ao } \\
\text { noroeste do Canadá }\end{array}$ & Mapa corporal \\
\hline A3 & Gelatti \& Angeli, 2019 & Brasil & $\begin{array}{l}\text { Pensar a percepção corporal de sujeitos com } \\
\text { sequelas de Acidente Vascular Cerebral } \\
\text { (AVC). }\end{array}$ & $\begin{array}{l}\text { Pessoas com sequelas físicas } \\
\text { em virtude do AVC, Unidade } \\
\text { Básica de Saúde, Brasil }\end{array}$ & $\begin{array}{l}\text { Cartografia e } \\
\text { mapa corporal }\end{array}$ \\
\hline A4 & $\begin{array}{l}\text { Maina, Sutankayo, } \\
\text { Chorney, \& Caine, } \\
2014\end{array}$ & Canadá & $\begin{array}{l}\text { Entender como indivíduos da área da } \\
\text { enfermagem experimentam o mapeamento } \\
\text { corporal como uma ferramenta de educação } \\
\text { em saúde. }\end{array}$ & $\begin{array}{l}\text { Jovens e estudantes de } \\
\text { enfermagem que vivem com } \\
\text { HIV ou convivem pacientes } \\
\text { soropositivos }\end{array}$ & $\begin{array}{l}\text { Entrevista em } \\
\text { profundidade e } \\
\text { mapa corporal }\end{array}$ \\
\hline A5 & $\begin{array}{l}\text { Dew, Smith, Collings, } \\
\text { \& Savage, } 2018\end{array}$ & Austrália & $\begin{array}{l}\text { Pesquisar sobre o uso do mapa corporal com } \\
\text { pessoas com necessidades complexas de } \\
\text { suporte. }\end{array}$ & $\begin{array}{l}\text { Pessoas com necessidades } \\
\text { complexas e/ou deficiência } \\
\text { cognitiva em uma ONG na } \\
\text { Austrália. }\end{array}$ & Mapa corporal \\
\hline A6 & $\begin{array}{l}\text { Davy, Magalhães, } \\
\text { Mandich, \& Galheigo, } \\
2014\end{array}$ & Canadá & $\begin{array}{l}\text { Compreender os facilitadores e as barreiras } \\
\text { para o sucesso de jovens refugiados no } \\
\text { assentamento no Canadá. }\end{array}$ & $\begin{array}{l}\text { Jovens refugiados de Ontário, } \\
\text { Canadá }\end{array}$ & Mapa corporal \\
\hline A7 & Skop, 2016 & Canadá & $\begin{array}{l}\text { Explorar experiências de saúde de homens e } \\
\text { mulheres com diagnóstico de fibromialgia. }\end{array}$ & $\begin{array}{l}\text { Pacientes diagnosticados com } \\
\text { fibromialgia no Canadá }\end{array}$ & $\begin{array}{l}\text { Entrevista em } \\
\text { profundidade, } \\
\text { mapa corporal e } \\
\text { grupo focal }\end{array}$ \\
\hline A8 & $\begin{array}{l}\text { Gubrium, Fiddian- } \\
\text { Green, Jernigan, } \\
\text { \& Krause, } 2016\end{array}$ & EUA & $\begin{array}{l}\text { Examinar as barreiras enfrentadas pelas } \\
\text { jovens a fim de desenvolver mensagens e } \\
\text { programas relevantes de apoio. }\end{array}$ & $\begin{array}{l}\text { Adolescentes grávidas de } \\
\text { baixa renda, nos Estados } \\
\text { Unidos }\end{array}$ & $\begin{array}{l}\text { Estudo } \\
\text { exploratório e } \\
\text { mapa corporal }\end{array}$ \\
\hline Total & 8 estudos & & & & \\
\hline
\end{tabular}


Todos os estudos analisados conferiram baixo risco de viés metodológico, sendo que dois receberam uma avaliação mediana $(65 \%)$ e os demais receberam uma avaliação alta (acima de 75\%). Pode-se inferir que o rigor dos estudos incluídos nesta metassíntese foi atendido, pois estão em consonância com os critérios de qualidade exigidos para atestar a confiabilidade e a relevância das publicações.

Os estudos revisados assinalaram inúmeros benefícios do uso do mapa corporal, que podem ser assim sintetizados: possui alta acessibilidade, não exige letramento e possui baixo custo em sua aplicação; serve como mediador para refletir, acessar e organizar experiências passadas, que são vividas, revividas e expressadas artisticamente; facilita a comunicação verbal e não-verbal e melhora a compreensão sobre as necessidades, percepções e experiências dos participantes; propicia o diálogo sobre temas difíceis, desafiadores ou tabus; gera autoconfiança no participante que se vê capaz de expressar e transmitir seus conhecimentos e sentimentos através da arte, ainda que não possua vocabulário ou profundidade de repertório linguístico; promove a autoestima e permite que o participante se reconheça, sinta e expresse gratidão por quem ele é como indivíduo, que se aceite mais, que se sinta fortalecido; ajuda no resgate e definição de sua origem, identidade cultural e étnica ("ensinou muito sobre nós mesmos" A4); encoraja o participante a pensar sobre os eventos e seu significado em sua vida, facilita a introspecção, a conexão pessoal, a realização do significado e o processamento de emoções ("reconhecer o eu e estar ciente da identidade é a realização final" A4); permite dar visibilidade às linhas de forças históricas, sociais e das narrativas pessoais que compunham os corpos em relação; "sinaliza a potência de reinventar-se" (A3); permite que os participantes marquem, identifiquem e reconheçam essas histórias invisíveis e anexem significados a elas; dá visibilidade a uma questão que está para além do indivíduo ("mas que constitui o terreno de possibilidade de seu existir" A3); gera possibilidades de se abrir para uma construção singular de novas narrativas; cria espaços seguros dentro das quais as relações são criadas e as experiências são compartilhadas ("é uma oportunidade de compartilhar experiências e de aprender a mudar de atitudes" A4). Uma única limitação foi apontada por um estudo como possível risco: o mapeamento corporal pode aumentar a auto-vulnerabilidade.

Há na literatura uma gama de possibilidades com finalidades diferentes no uso do mapa corporal. De acordo com Gastaldo et al. (2012), o mapa pode ser utilizado como instrumento terapêutico, técnica de pesquisa, instrumento para obter informações sobre tratamento e dar apoio, ferramenta de militância política, de diálogo intergeracional, de formação de equipes, de criação de arte ou biográfica. Nos artigos revisados, embora com propósito exclusivo do uso do mapa como instrumento de pesquisa, sobressai o caráter emancipatório e o protagonismo conferido aos participantes, que se dá por meio da apropriação de sua história narrada e literalmente corporificada no desenho.

Percebe-se que além da variedade de público que o mapa corporal pode alcançar, a modalidade de aplicação, em grupo ou individual, implica diretamente no contexto social que se apresenta, cabendo ao pesquisador saber fazer leituras subjetivas acerca dos participantes e da realidade em que vivem. No estudo que trata sobre pacientes com fibromialgia, por exemplo, a pesquisadora chama a atenção para a importância de se realizar a aplicação do mapa corporal em grupo, pois são pacientes que vivem a maior parte do tempo isolados, devido às fortes dores e limitações cotidianas. Dessa forma, o grupo revelou-se como um potencial para aumentar a conexão social e estabelecer laços de amizade entre os pacientes (Skop, 2016). Sob outro ponto de vista, pessoas em situação de extrema vulnerabilidade, que até o contato com o outro pode significar uma exposição perigosa, como é o caso de imigrantes e refugiados, a aplicação do mapa corporal de forma individual pode oferecer mais segurança pessoal e confidencialidade (Davy et al., 2014).

Os benefícios resultantes da aplicação do mapa corporal narrado assinalados pelos artigos revisados podem ser agregadas em três dimensões, que podem ser assim sintetizadas: 1) dimensão da comunicação, mediada pela linguagem visual e artística, que nos remete ao caráter de inovação criativa da metodologia; 2) dimensão relacional, que se estabelece no espaço de co-construção do mapa narrado e que se traduz em seu potencial terapêutico; 3) dimensão crítica e política, que comparece quando a corporeidade ganha voz, consciência e expressão, denunciando os lugares sociais e históricos que coube a essas populações em estudo.

Desse modo, com base nas evidências qualitativas dos artigos revisados, foram criadas três categorias de análise.

\section{A Inovação Criativa do Mapa Corporal}

Todos os artigos revisados assinalam para o aspecto inovador do mapa corporal que, ao oferecer formas de expressão das linguagens artística e visual, transpõe as barreiras de comunicação humana, favorecendo a produção de novos conhecimentos e habilidades: "A arte vai além das limitações das palavras, oferecendo uma forma de comunicação para transmitir a profundidade e complexidade das experiências corporais e emocionais" (A5). Tem-se que as atividades artísticas desenvolvidas com o propósito de arteterapia encontram ampla fundamentação científica sobre seus benefícios em saúde mental e têm sido utilizadas como dispositivo terapêutico em serviços de saúde, tendo em vista a valorização de formas singulares do processo de livre criação dos participantes, elevação da autoestima, melhora do equilíbrio emocional e minimização dos efeitos negativos da doença mental que a arteterapia promove (Coqueiro et al., 2010). 
As pesquisas revisadas também defendem que usar métodos baseados na arte em educação é um convite a acessar novos significados, além de fomentar a empatia e as conexões pessoais consigo mesmo e com os outros, permitindo um nível mais profundo de reflexão. Ao permitir o aprofundamento sobre as experiências, eles podem promover o crescimento e novas habilidades: "reconhecemos o papel da reflexão e introspecção na educação e na transformação pessoal (A2)". Por sua vez, os artigos apontam que o contato com essa forma peculiar de expressão artística, combinada com a narrativa, ajuda a produzir novas narrativas para o sujeito através do corpo. Para que a metodologia alcance seu propósito, a produção artística só fará sentido se vier acompanhada do relato reflexivo de seu criador sobre sua história e suas experiências vividas. De acordo com Yuen (2016), um significado artístico leva à emergência de uma compreensão multivocal, isto é, o que começa com uma metáfora simples, pode desembocar em múltiplas metáforas e compreensões.

Como expressão artística, o mapa corporal foi assinalado nos artigos revisados como via de simbolização e construção de novos significados, que cria a segurança necessária para tratar aspectos de diversas ordens, pessoais, emocionais, culturais, políticas e socioeconômicas de suas vidas (por exemplo, pessoas vivendo com HIV/aids se entregam à experiência da construção de seus mapas e se permitem enfrentar e ressignificar seus medos, preconceitos e atitudes). A arte como método de pesquisa e interpretação permite a fluidez de metáforas, o simbolismo e a comunicação interpretativa, fornecendo aos participantes oportunidades de compartilhar experiências, conhecimentos e compreensões de maneira flexível, dinâmica e natural (Yuen, 2016).

Os estudos também destacam resultados que impactam na forma como o problema de saúde é percebido: "mudança social foi promovida criativamente com os resultados da pesquisa e foram usados para gerar uma melhor compreensão da experiência de cuidados em saúde de pessoas com fibromialgia" (A7); "[o mapa corporal promove a] capacidade de envolver e transformar práticas, abrir discursos públicos e permitir que os alunos compreendam questões difíceis e complexas, como o HIV" (A4). Os métodos de pesquisa baseados em arte têm recebido crescente reconhecimento no campo de pesquisa social porque oferecem formas mais democráticas de participação, fomentando, assim, o engajamento e o empoderamento dos participantes (Boydell et al., 2012).

Para alcançar o estado ideal de produção criativa, alguns dos artigos recorreram a diferentes estratégias de aquecimento ou preparação prévia à confecção do mapa: relaxamento, meditação e/ou jogos corporais. Também se observou variação de modalidade de aplicação da metodologia (grupal ou individual) nos artigos revisados, embora nenhum deles tenha explorado o efeito dessa variação no processo criativo do participante. A maioria dos estudos previu, guardados os devidos cuidados éticos, a exibição pública dos mapas confeccionados, em salas de exibição, atividade comum ao meio artístico para o coroamento e compartilhamento da obra de arte. Para Yuen (2016), o uso de métodos artísticos em pesquisa pode ser associado a movimentos de resistência à opressão, indo além das margens e, por isso, defende que a exibição artística promove trocas sociais, propiciando o envolvimento das populações marginalizadas na sociedade como um todo. $\mathrm{O}$ impacto da exposição artística dos mapas não foi explorado nos estudos.

A conexão com o corpo é outro ponto que se destaca, dado que os corpos ganham expressividade para além da imagem corporal. As representações de autoimagem e autocuidado são produzidas em constante interação com o outro durante a construção do mapa corporal (Matos et al., 2018). De uma forma geral, observou-se que a maioria dos estudos tinha como público adolescentes e jovens, isto reflete uma faixa etária que frequentemente pode evidenciar comportamentos de timidez, insegurança ou inibição. Em contrapartida, o uso de desenhos para se expressar, bem como a criatividade perceptível nos desenhos, facilita a abertura dos sentimentos dos jovens para com o pesquisador e na própria relação com o seu corpo.

A questão da criatividade evocada em todos os estudos é um aspecto muito valorizado na metodologia do mapa corporal narrado, mas carece de maior consistência e aprofundamento nos estudos, tanto no que tange o seu processo quanto o seu produto. Outra lacuna constatada nos artigos revisados diz respeito a como realizar a análise dos resultados. Em se tratando de uma ferramenta não tradicional, soa um contrassenso utilizar metodologias de análise da pesquisa qualitativa tradicional na leitura dos resultados, o que foi observado em alguns estudos que utilizaram análise temática e entrevista de profundidade. No entanto, apenas um dos estudos faz menção à utilização de ferramentas das belas artes para a análise.

\section{O Potencial Terapêutico do Mapa Corporal}

A derivação do mapa corporal narrado de seu uso em arteterapia (MacGregor, 2009) para sua utilização como método de pesquisa (Gastaldo et al., 2018) não o esvaziou de seu potencial terapêutico originário. Todos os artigos revisados apontaram para um ou vários aspectos dos resultados que conferem propriedade terapêutica a essa metodologia, ainda que o tenham utilizado com o propósito de fazer pesquisa. "O mapeamento corporal tem valor terapêutico [...] Embora a condução da pesquisa de mapeamento corporal foi adaptada da arteterapia para método de pesquisa, o valor terapêutico do mapeamento corporal esteve ainda evidente." (A7).

Os aspectos terapêuticos atribuídos ao mapa corporal narrado foram diversos: ajuda a lidar com sentimentos de perda e luto, com os efeitos da depressão; promove a ressignificação de relações (com familiares e pares); 
promove a saúde mental e o bem-estar; propicia a escuta e a ampliação da consciência de corpo; estimula novas narrativas sobre si mesmo; explora a construção da identidade ("reconhecer o eu e estar ciente da identidade de alguém é a conquista final", A4); faz o participante entrar em contato com as narrativas produzidas, a perceber inúmeros "eus" dentro de si e aprender a lidar com eles ("podem coexistir verdades", A3); propicia o acesso às próprias experiências vividas, fazendo os participantes as reviver e as representar artisticamente; permite que os participantes marquem, identifiquem e reconheçam histórias invisíveis e atribuam significados a elas; promove o alívio de não se estar só em sua dor ("muitos participantes relataram que o processo de mapeamento corporal aumentou o senso de conexão sensorial porque foi a primeira vez que se deram conta de que não estavam sozinhos no seu sofrimento e que outros têm sintomas similares e lutas em cuidado com a saúde", A7); tira a pessoa do lugar de vítima: "tem o potencial de desviar a atenção de um enfoque negativo, no qual a fixação de problemas de saúde é codificada como 'saúde",", (A8); propicia a construção de um espaço de expressão de crenças, medos, histórias; promove ressignificação não só dos próprios sujeitos como do próprio espaço (dos serviços de saúde); desloca a centralidade do diagnóstico, observando os processos de constituição dos corpos e de suas narrativas; funciona como "catalisador, pois levou os participantes a discutir tópicos difíceis e ajudou muitos jovens a lembrar o que eles queriam dizer" (A2); estimula a produção de insigths que não surgem durante as abordagens tradicionais de pesquisa qualitativa e desperta questões que às vezes nem são pensadas pelo pesquisador quando realizam uma entrevista comum; e incita a postura crítica e reflexiva dos envolvidos.

Os estudos revisados também apontam que os efeitos do mapeamento corporal já se fazem sentir desde o início de sua aplicação por provocarem mais motivação e engajamento nos participantes. Além disso, ao longo da confecção do mapa foram reportadas sensações de calma e bem-estar por parte dos participantes.

A discussão sobre os efeitos terapêuticos dessa modalidade de pesquisa suscita uma preocupação adicional aos pesquisadores que não são profissionais da área "psi" e que, portanto, não estão aptos ao manejo de situações complexas de manifestações de intenso envolvimento emocional que podem ser disparadas ao longo da confecção do mapa corporal. "Sugiro que pesquisadores sejam treinados em facilitação de grupo para assegurar que os participantes se sintam emocionalmente seguros no mapeamento corporal. Se pesquisadores não tiverem treino em manejo de disparadores emocionais e estresse, eles precisam procurar suporte para oferecer aos participantes" (A7).

Porém, quando a ferramenta está de posse de pesquisadores com formação em psicologia clínica, a qualificação do pesquisador confere à metodologia uma capacidade exponencial de provocar vivências catárticas e terapêuticas, desde que não se desvirtuem os papéis em jogo e não se abandone um ou outro, o olhar clínico e sensível pode qualificar sobremaneira o acolhimento e encaminhamento necessários, tornando a complexidade da experiência ainda mais rica. "Há no fazer singular uma potência do novo que pode vir a fabricar novos enredos para a vida humana e modos de executar as atividades, neste sentido, uma potência clínica" (A3).

Por fim, cabe refletir sobre o espaço que se constrói na confecção do mapa corporal e que propicia a delicada relação entre pesquisador e participante: "um cuidado artesanalmente construído com cada um em sua singular expressão no mundo. Um modo de pensar a clínica que implica o terapeuta também em seu corpo-processo" (A3). Dessa forma, tanto o pesquisador quanto o participante são valorizados pela contribuição de seus conhecimentos específicos: o participante na geração e interpretação de seu mapa, e o pesquisador na identificação de temas, na análise, na síntese da teoria e na elaboração de conclusões (Guillemin \& Drew, 2010).

O mapa corporal é apontado como um instrumento com características muito positivas para a atuação do pesquisador e dos participantes, uma vez que possibilita uma ruptura paradigmática de distanciamento entre pesquisador e pesquisado, configurando-se como uma metodologia mais participativa, equânime e comunicativa. Os estudos também mostram o efeito catalisador que o mapa corporal pode produzir, por ser uma ferramenta educativa e reflexiva, que promove a construção de ideias e conhecimentos relativos a determinados assuntos, como também problematiza questões complexas para serem pensadas, desconstruídas, reconstruídas e disseminadas.

\section{- Mapa Corporal como Metodologia Emancipatória}

Os desafios lançados frente à realização de revisões sistemáticas de literatura no âmbito da pesquisa qualitativa são inúmeros, sobretudo diante da predominância histórica de métodos quantitativos nas produções científicas, que delimitou um campo dominante coroado como "padrão ouro" na sociedade capitalista eurocentrada. Configurou-se, então, como algo subversivo e passível de questionamentos no campo científico, as pesquisas qualitativas cujas características buscavam maior adensamento das realidades vivenciadas, bem como o olhar direcionado para populações historicamente marginalizadas e estigmatizadas no esteio social excludente. Não é raro, a partir de estudos que utilizam abordagens mais tradicionais de coleta de dados, encontrar pesquisas que geram conclusões simplistas que remetem esse público ao lugar de destituído de capacidade de produzir conhecimento profundo de valor heurístico. Cabe, então, problematizar se a limitação da produção de conhecimento está no método empregado e não nos participantes da pesquisa. 
Essa relação de demarcação de poder leva-nos a refletir que os contextos hierárquicos, baseados na experiência de colonização de povos, de nações e de saberes, perpetuam, sob a égide do poderio europeu, a produção de conhecimento traduzida pelo particularismo ocidental que foi reescrito como um universalismo global (Hall, 2003). O enfrentamento ao eurocentrismo, que apresenta o ethos europeu como verdade absoluta e universal do conhecimento, demanda esforços que estão circunscritos na reelaboração de concepções de mundo, nas quais torna-se necessário repensar sobre quem está autorizado a produzir conhecimento, a quem está endereçado e o que pode ser considerado válido.

O uso do mapa corporal como uma metodologia visual e criativa busca construir ressignificações subjetivas, além de permitir simultaneamente evidenciar questões identitárias, vivenciais e culturais, a partir das possibilidades iminentes de entrar em contato com a sua própria história, considerando a centralidade do seu próprio corpo. Todavia, as experiências relatadas por meio do uso do mapa corporal revelam elementos basilares que possibilitam construir e reconstruir compreensões acerca do que se sente, permitindo um mergulho profundo na subjetividade humana. "Corpos em evidência" (A8); o mapa corporal desafia a ciência a rever suas evidências: "muitas vezes nas pesquisas baseadas em evidências ocorre a exclusão de elementos contextuais e vivenciais, ignorando o que historicamente é impactado por injustiças históricas; no contexto da iniquidade em saúde" (A8). "Nós nos concentramos intencionalmente em corpos como evidência para desafiar a hegemonia do conhecimento especializado em torno da gravidez na adolescência e dos pais, que é criado através da produção de estatísticas, que emergem de um discurso de culpa e vergonha" (A8).

Nesse sentido, produzir saberes envolve transcender o paradigma de que não há um lugar único de produção do conhecimento, visto que esse saber deve emergir do lócus de enunciação a partir de quem o vivencia. "O valor de uma metodologia participativa, como o mapeamento corporal, é que, ao invés de ser um objeto a ser analisado e de extração de dados, o participante de pesquisa torna-se um co-criador de conhecimento e informação. Como co-criador, seu conhecimento, sua construção de significados e experiências vividas são valorizados como ativos." (A8).

O protagonismo e a autonomia dos participantes são elementos que compõem praticamente a totalidade dos trabalhos analisados. "Propõe a interação e participação ativa de profissional-paciente/pesquisador-participante, busca romper com a visão reducionista que ignora as especificidades do sujeito e o fragmenta quando o olhar é voltado apenas para a doença e não para a saúde" (A3). Isso demonstra como a ferramenta do mapa corporal atua na perspectiva de considerar o saber inerente ao indivíduo, a partir de seu corpo e de suas vivências, contribuindo para inverter a lógica de um único saber operante. "A pessoa habita um lugar de testemunho de quem narra, operando uma importante alteração nos lugares de poder habitados em potência por terapeutas e sujeitos do cuidado." (A3).

Ademais, com o mapa corporal torna-se possível articular e integrar a teoria e a prática, incita o participante a ser o ponto principal da pesquisa por meio da expressividade de suas opiniões, crenças, valores e sentimentos. Por outro lado, outros componentes que atravessam os sujeitos também devem ser considerados, como a compreensão política, social, espiritual e afetiva. Assim como indicam Dew et al. (2018), o mapeamento fornece uma maneira alternativa para os participantes se expressarem através de narrativas não-verbais, sendo fundamental para engajar criativamente grupos marginalizados e/ou com necessidades complexas de comunicação.

Com isso, sintetizar essas evidências qualitativas que revelam tentativas de rupturas de poder, indicam caminhos de diálogo e ressignificação do conhecimento, com vistas à abertura para epistemologias contra-hegemônicas que valorizem a construção do saber a partir das realidades locais vivenciadas. O mapa corporal, como peça fundamental para a produção de evidências qualitativas, contribui para reivindicar "o paradigma de superação do modelo médicopsicológico" (A3). "Meu interesse foi ajudar pessoas marginalizadas por fibromialgia, diminuir o estigma social e promover mudanças potenciais nas políticas de saúde. [...] O mapa corporal vai além do dualismo cartesiano do modelo médico ajudando os participantes a refletir sobre a conexão de suas mentes, corpos, sentimentos, pensamentos, experiências e interações sociais." (A7). A proposta do uso do mapa corporal em pesquisa coloca-se como ato de resistência, ou seja, na contramão da injustiça testemunhal - aquela que ocorre quando o sujeito é destituído de credibilidade por conta de um preconceito negativo de identidade por parte do ouvinte - e a injustiça hermenêutica, que ocorre quando um sujeito tem a sua capacidade de entender e expressar experiências limitadas por preconceitos de identidade estruturalmente estabelecidos de modo a obscurecer estas experiências (Fricker, 2007).

\section{CONSIDERAÇÕES FINAIS}

O mapa corporal revelou-se um grande potencial de uso da arte, pesquisa e criatividade de forma conjunta. Os estudos mostraram que os mapas podem oferecer caminhos acessíveis e inovadores para a pesquisa qualitativa, proporcionando formas de mergulhar na subjetividade dos sujeitos pesquisados, tirando-os do lugar de objeto para o de protagonistas de suas próprias histórias. Em suma, deixam de ser fonte de informação e passam a ser 
informantes, revertendo assim a lógica da exclusiva autoria do conhecimento com foco no pesquisador.

A pluralidade das narrativas advindas do mapa corporal é fonte de grande riqueza para o pesquisador, ao mesmo tempo em que se presta a mobilizar uma oportunidade de ressignificação para o sujeito participante. A possibilidade de entrar em contato com sensações, memórias e sentimentos muito particulares, que às vezes estão adormecidos ou até esquecidos, pode oferecer mudanças de rota e caminhos de transformação, nos quais aquilo que se apresentava de uma determinada maneira, começa a ser visto de forma diferente. Desse modo, por meio da construção de narrativas de vida mediadas pelo mapa corporal é possível dissolver o problema ético da injustiça que afeta os seres humanos enquanto sujeitos epistêmicos dotados da capacidade de produzir, possuir e repassar conhecimento, sobretudo através da prática do testemunho, devolvendo a centralidade do testemunho como evidência científica, e valorizando o corpo como evidência.

A potencialidade de produção de conhecimento científico derivado de estudos que utilizam o mapa corporal narrado, questão central desta revisão de literatura, mostrou-se significativa, embora o método seja muito novo e apresente ainda muitas lacunas a serem sanadas, dentre as quais, a sistematização da análise dos dados visuais e artísticos produzidos nesses estudos. Os conhecimentos derivados dos estudos revisados foram sintetizados em três fortes contribuições: (1) a inovação criativa do mapa corporal, embora ainda requeira fundamentação, (2) seu grande potencial terapêutico (o que o coloca como uma excelente ferramenta de pesquisa-intervenção em psicologia clínica e comunitária), e (3) sua afinada crítica ao discurso hegemonicamente instituído.

$\mathrm{O}$ fato de ser uma metodologia que promove um diálogo menos assimétrico entre pesquisador e participante faz dessa ferramenta uma forte aliada das perspectivas de pesquisa de cunho participativo e emancipatório. Nesse sentido, futuros estudos poderiam explorar a relação participantepesquisador, levando em consideração os respectivos lugares de fala, algo negligenciado nos artigos estudados.

Uma das limitações do estudo foi a decisão das pesquisadoras de excluir os artigos que não se encontravam disponíveis na íntegra, sem o devido pagamento. Essa escolha deveu-se a uma coerência ideológica das pesquisadoras, mais do que a uma questão econômica. Resulta que ambas as pesquisadoras defendem a difusão democrática do conhecimento e condenam a mercantilização dos produtos acadêmicos. Lamenta-se que o avanço de pesquisas que se prestam a melhorar a saúde e a qualidade de vida de seres humanos e, em especial de populações historicamente vulnerabilizadas pelo contexto, encontre barreiras na elitização de seu acesso.

Por fim, em se tratando de uma ferramenta destinada a coconstruir conhecimento junto a populações estigmatizadas, excluídas e vulnerabilizadas, sua utilização se reveste de extrema importância na produção de novos conhecimentos, haja vista a ausência de respostas criativas no cenário mundial de iniquidade e desigualdade social e, mais acentuadamente, no Brasil.

\section{REFERÊNCIAS}

Baerg, S. (2003). "Something there just aren't any words". Using expressive therapy living with cancer. Canadian Journal of Counselling, 37(1), 65-74. https://files.eric.ed.gov/fulltext/ EJ662445.pdf

Botha, C. S. (2017). Using metaphoric body-mapping to encourage reflection on the developing identity of pre-service teachers. South African Journal of Education, 37(3), 1-12. https://doi. org/10.15700/saje.v37n3a1377

Boydell, K. M., Gladstone, M. B., Volpe, T., Allemang, B., \& Stasiulis, E. (2012). The production and dissemination of knowledge: A scoping review of arts-based health research Forum: Qualitative Social Research, 13(1). https://doi. org/10.17169/fqs-13.1.1711

Critical Appraisal Skills Programme - CASP. (2018). CASP Checklist: 10 questions to help you make sense of a qualitative research [Oxford]: CASP [internet]. CASP UK. http://www. casp-uk.net/casp-tools-checklists

Coqueiro, N. F., Vieira, F. R. R., \& Freitas, M. M. C. (2010). Arteterapia como dispositivo terapêutico em saúde mental. Acta Paulista de Enfermagem, 23(6), 859-862. https://doi. org/10.1590/S0103-21002010000600022

Davy, C., Magalhães, L. V., Mandich, A., \& Galheigo, S. M. (2014). Aspects of the resilience and settlement of refugee youth: A narrative study using body maps. Caderno Brasileiro de Terapia Ocupacional, 22(2), 231-241. https://doi.org/10.4322/ cto. 214.045
Dew, A., Smith, L., Collings, S., \& Savage, I. D. (2018). Complexity embodied: Using Body Mapping to understand complex support needs. Forum: Qualitative Social Research, 19(2), 1-24. http://www.qualitative-research.net/index.php/fqs/ article/view/2929

Eakin, J. M. (2016). Educating critical qualitative health researchers in the land of the randomized controlled trial. Qualitative Inquiry, 22(2), 107-118. https://doi. org/10.1177/1077800415617207qix.sagepub.com

Ebersohn, L. (2015). Body mapping for resilience: Fostering adaptability with groups of youth in high risk and high need settings. In M. McMahon \& W. Patton (Eds.), Ideas for career practitioners: Celebrating excellence in career practice (pp. 82-89). Australian Academic Press.

Ferigato, S. H., Silva, C. L., \& Ambrosio, R. (2018). A corporeidade de mulheres gestantes e a terapia ocupacional: Ações possíveis na Atenção Básica em Saúde. Caderno Brasileiro de Terapia Ocupacional, 26(4), 768-783. https://doi.org/10.4322/25268910.ctoao 1173

Fricker, M. (2007). Epistemic Injustice: Power and the ethics of knowing. University Press.

Gastaldo, D., Carrasco, C., Magalhães, L., \& Davy, C. (2012). Bodymap storytelling as research: Methodological considerations for telling the stories of undocumented workers through body mapping. Migration Health. http://www.migrationhealth.ca/ sites/default/files/Body-map_storytelling_as_reseach_HQ.pdf 
Gastaldo, D., Rivas-Quarneti, N., \& Magalhães, L. (2018). BodyMap Storytelling as a health research methodology: Blurred lines creating clear pictures. Forum Qualitative Social Research, 19(2), 3. https://doi.org/10.17169/fqs-19.2.2858

Gelatti, M. D., \& Angeli, A. A. C. (2019). Um corpo: Cartografando trajetórias de vida de sujeitos com sequelas de acidente vascular cerebral. Caderno Brasileiro de Terapia Ocupacional, 27(1), 149-167. https://doi.org/10.4322/2526-8910.ctoao1697

Griffin, S. M. (2014). Meeting musical experience in the eye: Resonant work by teacher candidates though body mapping. Vision of Research in Music Education, 24, 1-28. USR Rider. http://www-usr.rider.edu/ vrme/v24n1/visions/Griffin_ Meeting_Musical_Experience.pdf

Gubrium, A. C., Fiddian-Green, A. Jernigan, K., \& Krause, E. (2016). Bodies as evidence: Mapping new terrain for teen pregnancy and parenting. Global Public Health. An International Journal for Research, Policy and Practice, 11, 618-635. https://doi.org/10.1080/17441692.2016.1143522

Guillemin, M., \& Drew, S. (2010). Questions of process in participantgenerated visual methodologies. Visual Studies, 25(2), 272-289. https://doi.org/ 10.1080/1472586X.2010.502676

Jager, A., Tewson, A., Ludlow, B., \& Boydell, K. M. (2016). Embodied ways of storying the self: A systematic review of body-mapping. Forum Qualitative Social Research, 17(2), 22. http://nbn-resolving.de/urn:nbn:de:0114-fqs1602225

Joanna Briggs Institute for Evidence Based Practice - JBI. (2014). Reviewers 'manual [Internet]. http://www.joannabriggs.org

Hall, S. (2003). Da diáspora: Identidades e mediações culturais. Editora UFMG.

Lockwood, C., Porrit, K., Munn, Z., Rittenmeyer, L., Salmond. S., Bjerrum, M., Loveday, H., Carrier, J., \& Stannard, D. (2017). Chapter 2: Systematic reviews of qualitative evidence. In E. Aromataris \& Z. Munn (Eds.), Joanna Briggs Institute Reviewer's Manual (pp. 00-00). The Joanna Briggs Institute. https://reviewersmanual.joannabriggs.org/

Lopes, A. L. M., \& Fracolli, L. A. (2008). Revisão sistemática de literatura e metassíntese qualitativa: Considerações sobre sua aplicação na pesquisa em enfermagem. Texto \& Contexto Enfermagem, 17(4), 771-778. https://doi.org/10.1590/S010407072008000400020

Lys, C., Gesink, D., Strike, C., \& Larkin, J. (2018). Body Mapping as a youth sexual health intervention and data collection tool. Qualitative Health Research, 28(7), 1185-1198. https://doi. org/10.1177/1049732317750862

MacGregor, H. N. (2009). Mapping the body: Tracing the personal and the political dimensions of HIV/AIDS in Khayelitsha, South Africa. Anthropology and Medicine, 16(1), 85-95. https:// doi.org/10.1080/13648470802426326

MacGregor, H., \& Mills, E. (2011). Framing rights and responsibilities: Accounts of women with a history of AIDS activism. BMC International Health and Human Rights, 11(Supp 3), 1-11. https://doi.org/10.1186/1472-698X-11-S3-S7

Maina, G., Sutankayo, L., Chorney, R., \& Caine, V. (2014). Living with and teaching about HIV: Engaging nursing students through body mapping. Nurse Education Today, 34(4), 643647. https://doi.org/10.1016/j.nedt.2013.05.004

Matos, J. A. V., Silva, K. L., \& Garcia, M. C. (2018). Body-map storytelling: Research experience report with theoretical contribution of Bourdieu. Escola Anna Nery, 22(3), e20170407. https://doi.org/10.1590/2177-9465-ean-2017-0407

Mercado, F. J., Gastaldo, D., \& Prado, M. L. (2018). Colaboração Ibero-americana em Pesquisa Qualitativa em Saúde: Desafios e perspectivas. Texto \& Contexto, 27(3), 1-2. http://www.scielo. br/pdf/tce/v27n3/0104-0707-tce-27-03-editorial.pdf

Minayo, M. C. S. (2013). O desafio do conhecimento: Pesquisa qualitativa em saúde. Hucitec.

Mitchell, L. M. (2006). Body and illness: Considering Visayan Filipino children's perspectives with local and global relationships of inequality. Medical Anthropology, 25(4), 331373. https://doi.org/10.1080/01459740601025856

Moher, D., Liberati, A., Tetzlaff, J., Altman, D. G., \& The PRISMA Group (2009). Preferred reporting items for systematic reviews and meta-analyses: The PRISMA statement. PLoS Med 6(7), e1000097. https://doi.org/10.1371/journal.pmed.1000097

Murasaki, A. K., \& Galheigo, S. M. (2016). Juventude, homossexualidade e diversidade: um estudo sobre o processo de sair do armário usando mapas corporais. Cadernos Brasileiros de Terapia Ocupacional, 24(1), 53-68. https://doi. org/10.4322/0104-4931.ctoAO0648

Packer, M. (2011). The science of qualitative research. Cambridge Press.

Ramsuran, A., \& Lurwengu, F. (2008). Relations of power in different spaces: An exploration of the schooling experiences of children in an HIV/AIDS context. Journal of Psychology in Africa, 18(3), 393-399. https://doi.org/1080/14330237.20 08.10822011

Sandelowski, M., \& Barroso, J. (2007). Handbookfor synthesizing qualitative research (1st ed.). Springer Publishing Company.

Senior, K., Helmer, J., Chenhall, R., \& Burbank, V. (2014). 'Young clean and safe?' Young people's perceptions of risk from sexuality infections in regional, rural and remote Australia. Culture, Health \& Sexuality: An International Journal for Research, Intervention and Care, 16(4), 453-466. https://doi. org/10.1080/13691058.2014

Skop, M. (2016). The art of body mapping: A methodological guide for social work researchers. Aotearoa New Zeland Social Work, 28(4), 29-43. https://anzswjournal.nz/anzsw/article/ view/295/356

Sousa, M. S. A., Wainwright, M., \& Soares, C. B. (2019). Síntese de evidências qualitativas: Guia introdutório. BIS - Boletim do Instituto de Saúde, 20(2), 7-22. http://www.saude.sp.gov. $\mathrm{br} /$ resources/ instituto-de-saude/homepage/bis

Sweet, E. L., \& Escalante, S. O. (2015). Bringing bodies into planning: Visceral methods, fear and gender violence. Urban Studies, 52(10), 1826-1845. https://doi.org/10.1177/0042098014541157

Tarr, J., \& Thomas, H. (2011). Mapping embodiment: Methodologies for representing pain and injury. Qualitative Research, 11(2), 141-157. https://doi.org/10.1177/1468794110394067

Willis, N., Mavhu, W., Wogrin, C., Mutsinze, A. \& Kagee, A. (2018). Understanding the experience and manifestation of depression in adolescents living with HIV in Harare, Zimbabwe. Plos One, 3, 1-11. https://doi.org/10.1371/journal.pone.0190423

Yuen, F. (2016). Collage. Journal of Leisure Research, 48(4), 338346. https://doi.org/10.18666/JLR-2016-V48-I4-6922 